\title{
Learning Outside Classrooms on Campus Ground: A case study in Malaysia
}

\author{
Norhati Ibrahim, Nur Hafisah Fadzil, Masran Saruwono \\ Centre for Environment-Behaviour Studies (cE-Bs), Faculty of Architecture, Planning and Surveying, \\ Universiti Teknologi MARA 40450 Shah Alam, Selangor D.E., Malaysia \\ norhati@salam.uitm.edu.my
}

\begin{abstract}
This paper reports an assessment on a physical informal learning environment at a public university in Malaysia. The physical aspects investigated were the space conditions and utilisation that support informal learning activities undertaken by students outside their formal lecture hours. The research was conducted to understand how existing university facilities accommodate informal learning, through the use of observational and field inventory survey techniques. The study shows that an existing traditional university setting could accommodate a range of informal learning activities, for a limited percentage of the university population. The setting for learning could be better improved through the creation of more varied space conditions for varying learning activities and engagement intensity. It also asserts that quality learning environment should go beyond fulfilling functional needs, and cater for the learner's emotional need for inspiration and sense of identity.
\end{abstract}

Keywords: Learning; Informal setting; Higher education

eISSN 2398-4295 @ 2018. The Authors. Published for AMER ABRA cE-Bs by e-International Publishing House, Ltd., UK. This is an open-access article under the CC BY-NC-ND license (http://creativecommons.org/licenses/bync-nd/4.0/). Peer-review under responsibility of AMER (Association of Malaysian Environment-Behaviour Researchers), ABRA (Association of Behavioural Researchers on Asians) and CE-Bs (Centre for EnvironmentBehaviour Studies), Faculty of Architecture, Planning \& Surveying, Universiti Teknologi MARA, Malaysia.

DOI: http://dx.doi.org/10.21834/ajbes.v3i9.68 


\subsection{Introduction}

Nowadays university education has become extremely vital where attainment of a university degree is regarded as a foundation towards a secured future for individuals and well being of a society (Faust, 2012). Many factors are affecting change to university systems. They need to remain relevant responding to the demand for mass education, the changing needs of the digital age learners, and the challenges to produce quality graduates. Several past studies have presented evidence on the positive impact of the physical environment on learners for example, in terms of improved learning possibilities (Strange \& Banning, 2001) and higher student engagement (Dopplet, Mehalik, Schunn, Silk, \& Krysinski, 2008). Historically, university campuses have been shaped by the emphasis on traditional instructional methods, centered on formal learning approaches namely lecturing and tutorials. In recent years, several key factors have affected change in teaching and learning approaches. Among them is the fast pace development in the Information and Communication Technology (ICT) tools that enable fast, borderless knowledge transfer, access and distribution. This phenomenon challenges the traditional means of educational delivery approaches in particular and the university system as a whole. Typically an educational system nowadays incorporates three types of learning structure - instructional learning, informal learning and practice based learning. While it is clear that instructional and practice based learning take place primarily on campus and at the work place respectively, informal learning could take place in the physical and virtual environments, within or off campus.

Currently, how campus setting accommodates informal learning activities in the Malaysian universities remains unexplored. This paper aims to contribute towards this literature shortage, through evaluation of a learning environment setting in a public university in terms of its utilisation and student experiences. The paper examines aspects of the physical learning environment that support self directed learning within a campus setting. The main question asked in this research was whether or not an existing university setting, designed based on the traditional educational system, can accommodate the current learning needs.

\subsection{Literature Review}

Learning spaces can be understood from three interrelated perspectives namely the pedagogy, space and technology. The interrelationship between these three parameters was suggested by Oblinger (2004) and later developed into a framework for the creation of a learning environment, referred to as the Pedagogy-Space-Technology (PST) by Radcliffe (2008). Radcliffe further asserts that while there are general design rules on how to create a good learning environment, specific details would depend on the respective university's objectives and its stakeholders.

Traditionally and for many years the pedagogy of a university education revolved around structured teaching and deliveries in the form of lectures and tutorials. However by the beginning of 1990s the concept of 'learning' as opposed to 'teaching' was coined in (Barr \& 
Tagg, 1995; O'Neill \& McMahon, 2005), and has since, became common practice in many universities in the developed countries. The learning paradigm implies that students are expected to spend a significant amount of their typical study time outside-classroom environment. This approach is relatively new in Malaysia. It is currently gaining wide acceptance amongst institutions of higher learning in the country. Commonly referred to as Student Centred Learning (SCL), this approach regards student to be central to learning. $\mathrm{SCL}$ is seen as a mechanism to produce better quality graduates, who are critical, matured, and ready for the job market.

There are many literatures that have examined aspects of physical spaces that support learning activities as reviewed by Temple (2007) and the Australian Learning and Teaching Council (2010). There is, however, lesser literature that focuses on informal learning setting in particular. Fisher (2005) recommends informal learning spaces to be located near classrooms and other gathering places to increase the use. Further, he categorises informal learning setting according to 'breakout spaces', outdoor learning space, group learning space, and individual pod. These spaces are to be appropriately located to achieve functional efficiency as well as favourable learning and engagement stimulation.

Physical aspects of learning space include the size of space, furniture, seating arrangement, and availability of ICT tools (Hunley \& Schaller, 2006). Conducive conditions for informal learning identified to include flexibility, comfort and ergonomic seating, 'noise zone', food and drink, and pervasive technology (Acker \& Miller, 2005). Other literature asserts similarly adding that the spaces should be 'future-proofed, bold, creative, supportive and enterprising' (Joint Information Systems Committee (JISC), 2006). It is not just about fulfilling functional needs, but also stimulation of positive emotion, to encourage learning (Brown, 2005).

In terms of ICT tools, the literature highlights the need for learning spaces to be fully equipped with digital technology and infrastructure. As observed by Lomas and Oblinger (2006), students nowadays regard convenience as a priority. They demand continuous internet access, without which they will be restless. Learning space would need to accommodate multimedia technologies that extend further the students learning potentials.

\subsection{Methodology}

The study was conducted using the observation technique, aided with an observational sheet, a digital camera and a layout plan. Observation focused on space occupancy and utilization. Prior to the observation, a pilot survey and an inventory study were conducted which lasted for 7 days. This served to identify frequently occupied learning spaces. The study extended over three semesters during a typical study session, covering weekdays and weekends. The observations on these four settings were conducted using walkthrough technique - a commonly used method for occupancy evaluation of building-in-use. Each walkthrough lasted between 30 minutes to 1 hour. The observations were recorded by a group of 4 observers on observational sheets developed based on criteria suggested by Hunley \& Scaller (2006) and Oblinger (2004). The observations were performed within three periods - between 7:00 am to 12:00pm, 12:00pm to $5: 00 \mathrm{pm}$, and 5:00pm to 10:00pm. 
The chosen study context is located in the central area of a public university in Malaysia, located within the vicinity of four main academic blocks, the university's main library and cafeteria. The informal learning settings under observation are within the range of 250 metres from the main library. The buildings located in the area are among the earliest in the university, occupied since 1972. They house instructional learning spaces (lecture rooms, laboratories, auditoriums, and audio visual rooms) and supporting spaces namely, offices and meeting rooms and lecturers' rooms. The academic blocks serve the university community who work and study at four faculties which holds close to 4900 student enrollment.

There have been several recent refurbishments performed on the buildings and the surroundings. The library was recently refurbished involving changes to the internal space arrangements and furnishings. Spaces in the library are now more defined, designated according to the nature of learning activities. A common space was introduced for discussion. This is considered a major move from previous policy where most spaces in the library were considered as 'silent' zone. Enclosed discussion rooms were also introduced which are open to students for reservation. In order to make way to the new designated spaces, there is reduced number of single cubicles. The new furniture is of standard type, arranged in open plan layout.

Recent refurbishment on the cafeteria focused on the upgrading of the wall and floor finishes. The dining area in the cafeteria is quite cramped up with chairs and tables to maximise occupancy. Outdoor eating area was recently introduced with bench type seats and tables. Pockets of outdoor spaces at the corridors and plazas of the academic blocks have also recently been introduced with seats and tables.

\subsection{Findings and Analysis}

The field survey identified four main pockets of informal study area designated as F1, F2, F3 and F4 (refer to Figure 1 for layout). The following briefly describes the physical characteristics of each space.

\section{F1- 'Breakout space'(fully enclosed, air-conditioned open plan study room).}

F1 (study room). An open planning space with furniture arranged in rows to maximize the number of occupancy. Two sides of the perimeter wall are opaque, and the other two are glazed from sill to ceiling height. This permits entry of a good amount of natural light. The tables and chairs are loose-type, which allow students to move them around and rearrange them according to their needs. This behaviour was recorded during the observation period. Users' experiences in the space are independent reading / browsing/ searching through books, computers or other digital devices, as well as table discussion in small group. Most students appear to be regularly interacting with their media gadgets.

Fisher (2005) recommends accommodation of a variety of group learning sizes ranging from individual (1), small group size (3-15), team size (5-10), and large group size (15-35). This room is good for small group size between 2-6 people. Overall, the space caters for the needs of students to perform basic learning activities, ranging from passive to medium level 
discussion.

\section{Case study: Campus A}

Selection criteria The University's oldest central student zone.

Site plan

General view

Informal / self-
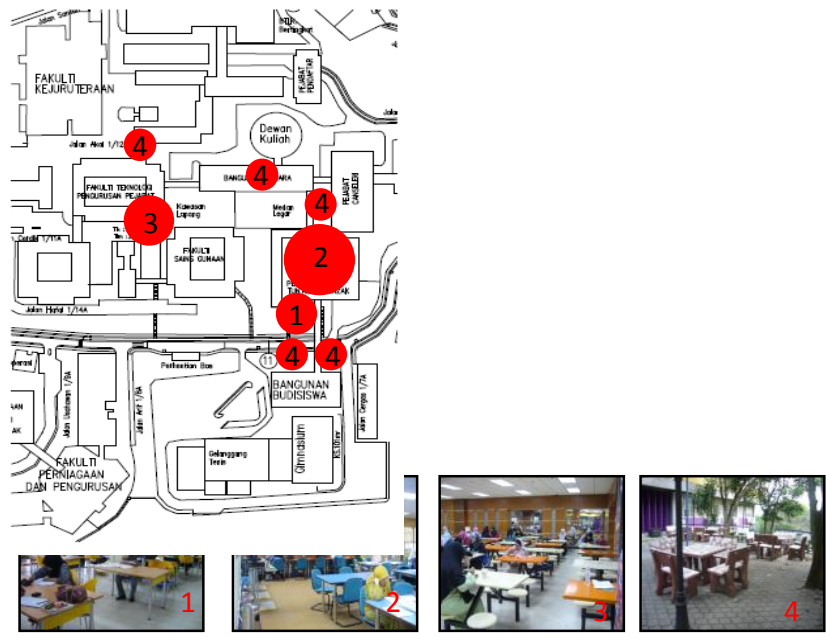

directed learning
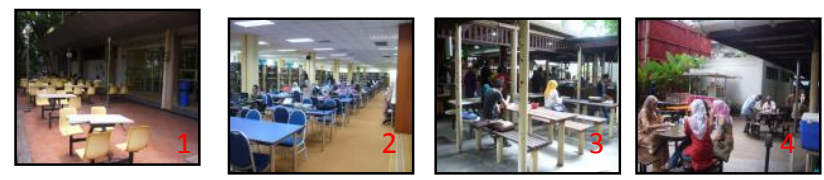

settings

1 'Breakout space' - open plan type small study room (enclosed and open space)

2 Library - open plan type reading area for individual or group learning (enclosed space)

3 Cafeteria - individual or group learning (enclosed and open space)

4 Outdoor learning space with pockets of designated seats (open space)

Figure 1: Summary of the four physical settings that serve as favourite informal learning pockets

\section{F2- Library - individual or group learning space (enclosed space)}

The informal learning space identified as F2 is within the University's main library. The seating arrangements range from individual pot for serious studying, to the common lounge 
for light reading. The common areas in the library are located at level one and level two. Seats in the lounge area are sofa type comprising single seater, double seater, side table and coffee table. This is a favourite place for students to linger, read the newspaper or watch television. The common reading areas offer a variety of seating choices, such as a rectangular and round table for four, table for one, and individual pod with divider for increased privacy.

\section{F3-Cafeteria - individual or group learning (enclosed and open space)}

$\mathrm{F} 3$ is the cafeteria area that offers indoor and outdoor pockets with potential to accommodate more active learning activities. The indoor area of the cafeteria tends to be overcrowded during peak hour (within $12 \mathrm{pm}$ to $5 \mathrm{pm}$ ), which tends to cause frequent episodes of discomfort. The outdoor seating area appears to be a favourite spot where students tend to engage in longer leisurely conversation among peers.

\section{F4-Pockets of outdoor learning space}

F4 are several pockets of outdoor spaces that are frequently used by students. The open plazas serve well as the circulation area, and as common ground for socializing and interaction. There are tropical trees and plants surrounding the outdoor sitting area that environmentally protects these pockets of learning spaces. Favourite areas are the one that receive good diffused natural light, ventilation and protection from direct sun and rain.

\subsection{Discussion}

The findings from this survey lead to suggestions on four key aspects of the physical environment that support informal learning on the campus ground.

- Environmentally protected spaces for varying learning activities

Informal learning could happen in many parts of a campus ground, occupying indoor, as well as pockets of environmentally protected outdoor spaces. Air conditioned indoor environment such as the library and designated study rooms are the preferred environment for private and small group learning. Students perform individual or private learning activities such as reading, writing and internet searching, as well as low intensity group discussion. Generally the informal learning spaces in the library and the designated study area are observed to be highly occupied at all time. The open plan type space arrangement provides flexibility to modify the space conditions to meet their changing study activities. However, the open plan type arrangement also reduces the opportunity for louder, active learning engagement such as brainstorming and debates.

\section{- $\quad$ Furniture for learning}

The most basic provision for learning is seating and table tops. Chair type and seating arrangements need to be appropriate to accommodate different types of learning activities. As observed by Oblinger (2004), informal learning can also happen at outdoor spaces as long as there are some forms of seating provisions such as bleachers, bench and amphitheater steps. Seats available on campus ground are in the form of chairs, settee, 
benches as well as steps. Provision of seats in outdoor space is limited in terms of quantity and variety of grouping / arrangements. This reduces the range of learning experiences that could take place at these informal learning pockets. Screens and white boards are essential to encourage more engaging learning activities such as brainstorming and discussions. Such furnishing support is not readily available.

\section{- ICT Tools and Learning Equipment Suggestions}

Students' learning activities involve the use of computer at most time. Seats which allow access to a power outlet is the preferred location. Accessibility to equipment commonly used by students such as printers, scanners and LCD screens are also desirable to aid their learning processes. In many instances, students were seen to be awkwardly crowding themselves around a small computer screen during group discussions, which appear to be uncomfortable.

- Beyond functional needs

Quality learning environment should go beyond functional needs, so as to fulfill current generation's appetite for individuality and sense of identity. Students interviewed voiced their need for better space conditions through the introduction of design elements that are different from the standard type furnishings.

\subsection{Conclusion}

A university is to serve its core community, namely the students and society at large. While attempting to address the demand for mass education, a public university has to assure that the quality of its graduates is not compromised. Physical learning setting in the university is an essential ground for learners to be engaged with fellow learners and academics. As suggested by Fischer (2005), 'learning is socially constructed and that people still want to be part of a community of learners'.

This study accounts for how students utilise a campus physical setting to perform informal learning activities on the campus ground within the premise of a public university in Malaysia. As asserted by Oblinger (2004), enabling student learning should be key occupation of a college or university. Malaysia aspires to be known as an education hub in the immediate future through adoption of SCL as the pedagogical strategy to produce excellent graduates. SCL means that the physical setting outside classroom is equally important compared to classrooms and lecture theatre. Informal learning can take place in many parts of a university ground, indoor as well as outdoor where there are good seats, access to ICT connection and sufficient protection from outdoor environmental discomforts. Controlled air conditioned indoor environment is the favourite choice among students. Learning activities within these spaces support private, individual and small group learning. Pockets of well shaded outdoor area are potential spaces to be improved further to enable engaging learning experiences.

The study shows that an existing traditional university setting could accommodate a range of informal learning activities for a limited percentage of the university population. The setting for learning could be better improved through the creation of spaces to accommodate 
intense group working experiences, which is currently lacking. Further to this, the current setting is short in emotional significance as students voiced their need for more appealing, bold and creative range of furnishings. This is a challenge especially for an existing public university that faces constraints in space for expansion and funding to create more stimulating, attractive learning spaces. This paper presentation is limited to analysing the initial results of an ongoing study based on a single area of learning setting. Nevertheless the finding contributes towards establishing evidence on the contribution of design characteristics towards user's learning activities and experiences.

\section{Acknowledgement}

The authors wish to thank the Ministry of Higher Education Malaysia (MOHE) for funding of this research project under the Exploratory Research Grant Scheme (ERGS), 2011. Also, their gratitude goes to Universiti Teknologi MARA (UiTM) for the infrastructure support, particularly the Research Management Institute (RMI) and the Faculty of Architecture, Planning and Surveying.

\section{References}

Acker, R., \& Miller, M. (2005). Campus Learning Spaces: investing in how Students Learn. Educause Centre for Applied Research, ECAR Research Bulletin, 8.

Australian Learning and Teaching Council (ALTC). (2010). Retrofitting university learning spaces Promoting excellence in higher education.

Barr, R., \& Tagg, J. (1995). A New Paradigm for Undergraduate Education from Teaching to Learning. Change, pp. 13-25.

Brown, M. (2005). Learning space design: Theory and practice. 40(4).

Dopplet, Y., Mehalik, M., Schunn, C., Silk, E., \& Krysinski, D. (2008). Engagement and achievements: A case study of design-based learning in a science context. Journal of Technology Education, 19(2), 21-38.

Faust, D. (2012). The role of the University in a changing world. Retrieved from http://www.harvard.edu/president/role-univerity-changing-world

Fisher, K. (2005). Pedagogy \& Space: Aligning Learning \& Learning Environments.

Hunley, S., \& Schaller, M. (2006). Assessing Learning Spaces. In D. Oblinger (Ed.), Learning Spaces: EDUCAUSE.

Joint Information Systems Committee (JISC). (2006). Designing spaces for effective learning: a guide to 21 st century learning space design: Higher Education Funding Council for England (HEFCE).

Lomas, C., \& Oblinger, D. (2006). Student practices and their impact on learning spaces. In D. Oblinger (Ed.), Learning spaces: EDUCAUSE.

O'Neill, G., \& McMahon, T. (2005). Student-centred learning: Ehat does it mean for students and lecturers? In G. 
Norhati, l., et.al. / Asian Journal of Behavioural Studies (AjBeS), 3(9) Jan / Feb 2018 (p. 131-139)

O'Neill, S. Moore \& B. McMullin (Eds.), Emerging Issues in the Practice of University Learning and Teaching. Dublin: Dublin:AISHE.

Oblinger, D. (2004). Leading the transition from classrooms to learning spaces: An NLII White Paper In N. L. I. I. (NLII) (Ed.), An EDUCAUSE Program.

Radcliffe, D. (2008). A Pedagogy-Space-Technology (PST) framework for designing and evaluating learning places. Paper presented at the Learning spaces in higher education: Positive outcomes by design, Brisbane.

Strange, C. C., \& Banning, J. H. (2001). Educating by design. San Francisco: Jossey-Bass.

Temple, P. (2007). Learning spaces for the 21st century: A review of the literature. The Higher Eudcation Academy, July. 